\section{Universitetet i Bergen}

www.uib.no/info/dr_grad/

Olav Thorsen, ph.d. General practitioners' referrals to specialist health services. Exploring elements and factors in the referral process having an impact on patients' access to specialty care. Utgår fra Institutt for global helse og samfunnsmedisin. Disputas 24.1. 2017.

Bedømmelseskomité: Frede Olesen, Aarhus Universitet, Danmark, Olav Helge Førde, Universitetet i Troms $\varnothing$ - Norges arktiske universitet, og Anne Kjersti Daltveit, Universitetet i Bergen. Veiledere: Anders Bærheim, Jan Olav Johannessen, Lars Fosse og Odd J. Kvamme.

Jan Roger Olsen, ph.d. Context dependent transcription factor regulation in normal and malignant cell differentiation. Utgår fra Klinisk institutt 2. Disputas 27.1. 2017.

Bedømmelseskomité: Norman J. Maitland, University of York, Storbritannia, Juha Klefström, University of Helsinki, Finland, og Vidar Bakken, Universitetet i Bergen.

Veiledere: Karl-Henning Kalland, Xisong Ke og Anne Margrete $\emptyset y a n$.

\section{NTNU}

Det skapende universitet

http://www.ntnu.no/kalender\#tag=disputaserdmf

Tarje Onsøien Halvorsen, ph.d. Thoracic radiotherapy in limited disease small cell lung cancer. Utgår fra Institutt for kreftforskning og molekylær medisin. Disputas 27.1. 2017.

Bedømmelseskomité: Jan Nyman, Sahlgrenska Universitetssjukhuset, Göteborg, Sverige, Lotte Victoria Rogg, Oslo universitetssykehus, Ullevål, og Heidi Knobel, Norges teknisk-naturvitenskapelige universitet.

Veiledere: Bjørn Henning Grønberg og Stein Kaasa.

\section{MELDTE DØDSFALL}

Jørgen Junkichi Jørgensen 7.2. 1947-14.1. 2017

Bernt Helmer Dahl 25.1. 1939-12.1. 2017

Tone Bohmann 18.1. 1945-7.1. 2017

Einfrid Perstølen 15.6. 1917-7.1. 2017

Thomas Hans Henrik Knoff 7.12. 1931 -19.12. 2016 